\title{
Railway usage charges based on marginal maintenance costs
}

\author{
Marjan Sternad PhD \\ Assistant Professor, Academic Unit for Supply Chain and Sustainable \\ Transport, Faculty of Logistics, University of Maribor, Celje, Slovenia \\ (corresponding author: marjan.sternad@um.si) \\ Timotej Jagrič PhD \\ Full Professor, Department of Quantitative Economic Analysis, Faculty of \\ Economics and Business, University of Maribor, Maribor, Slovenia
}

\author{
Bojan Rosi PhD \\ Full Professor, Dean, Academic Unit for Supply Chain and Sustainable \\ Transport, Faculty of Logistics, University of Maribor, Celje, Slovenia
}

The study reported here focused on finding a charging model for using regional railway lines. Due to geographical and technological characteristics, such lines are neglected and unused yet have great potential, especially for freight transport. The goal of the research was to calculate marginal maintenance costs of regional rail lines using an econometric cost function model. The econometric model was estimated using the least-squares method. The charges were calculated based on marginal costs and gross tonne kilometres (grt.km) and a comparison was made with the existing model for calculating charges. The grt.km calculation resulted in a charge lower than that calculated using the existing model, resulting in positive economic effects for carriers. The results of the proposed model are also in line with European transport policy objectives that strive to increase rail freight transport and redirect the flow of goods from road to rail, thus significantly lowering external costs.

\section{Notation}

$a_{j} \quad$ parameters that have to be estimated

C variable maintenance costs, which includes the costs of ordinary and major maintenance on railway infrastructure

$C_{\mathrm{vl} . \mathrm{km}} \quad$ price per train-km based on full cost

$C_{\mathrm{vp}} \quad$ cost of supplement or deduction for the type of transport (depending on the type of train)

$F_{\mathrm{vv}} \quad$ coefficient of power vehicle categories (vv)

$\mathrm{MC}_{\mathrm{grt} . \mathrm{km}, i}$ price per gross tonne kilometre (grt.km) at section $i$ based on marginal costs

$P_{i} \quad$ weighting of line category $i$

$Q_{\text {grt.km }} \quad$ amount of grt.km on regional rail

$Q_{\mathrm{vl} . \mathrm{km}(\mathrm{vv}, i)} \quad$ number of train-km per individual line category $(i)$ with the same power vehicle (vv)

$U \quad$ usage charge

$\varepsilon_{i} \quad$ error terms

\section{Introduction}

In Europe, infrastructure policy in the field of railway transport is directed by the European Union (EU), which releases guidelines for future transport development in EU Member States. European transport policies from 2001 (EC, 2001) and 2011 (European Commission, 2011) promote greater use of rail transport due to lower negative environmental impacts compared with road transport. European legislation (EC, 1991, 2012) provides for separate infrastructure management and transport services. Baumstark and Bonnafous (ECMT, 1998) argued that vertical separation is linked to the role of the state. However, Quinet (2001) stipulated that political decisions do not include the efficient use of railway infrastructure. Based on the adoption of four series of railway packages, the market for railway services in the international environment has gradually started to open up. This has resulted in an increase in competitiveness due to the larger number of rail service providers. Given the scarcity of infrastructure and monopoly positions, a system of charging was gradually set up that is based on different approaches with the aim of increasing efficiency. For this purpose, numerous studies on the choice of charging system for the use of railway infrastructure were conducted (Andersson, 2008; ECMT, 2005; Nash, 2005). Van de Velde et al. (2012) found no evidence that vertical separation increases competition compared with a holding company model and, likewise, no proof that such increased competition would reduce costs.

Within the framework of existing legislation, EU Member States can determine their own infrastructure policy and charging systems, allowing efficient operation and optimum utilisation. However, efficiency is harder to achieve over the whole rail network as the demand for rail services is unevenly distributed. Moreover, the choice of transport mode also affects the quality of transport services.

In practice, different approaches, based on the cost of infrastructure and demand for rail services, are used. A marginal social cost (Li and Preston, 2015) charging approach accounts for additional costs to society caused by each transported kilometre on the railway infrastructure (ECMT, 2005). Marginal social costs are the sum of marginal private costs, which in fact are costs of infrastructure management, and marginal external costs (environmental costs, accident costs and so on). Marginal social costs can include the costs of increasing capacity utilisation, including increased delays to other operators and scarcity costs (Johnson and Nash, 2008). Scarcity and congestion 
occur on the rail network when and where capacity utilisation is high (Nash and Matthews, 2003). Due to lack of competitiveness of the rail system compared with road, marginal external costs often do not apply to the charge for the basic railway infrastructure as this would lead to a further increase in costs, particularly on regional routes, which - due to the deteriorating economic situation - are still uncompetitive and thus unattractive to carriers.

In economic theory, various cost function alternatives for evaluating the cost of rail transport are in place. The transcendental logarithmic function (translog) developed by Christensen et al. (1973) was considered as a breakthrough in the field of assessing rail transport costs. Using this method, the theory of production and limits of the homogeneity of the production function were tested. Brown et al. (1979) used a transcendental function to calculate the marginal costs of rail transport. They found that the use of the neoclassical approach is appropriate when estimating costs. The neoclassical approach assumes that firms are technically efficient and they want to maximise profit. The transcendental logarithmic function has also been used to evaluate the marginal cost of infrastructure maintenance. Johansson and Nilsson (2004) estimated limit maintenance costs in Sweden and Finland and found that the transcendental specification and the link between maintenance costs and explanatory variables offer a good basis for understanding the costs of infrastructure maintenance.

When estimating the marginal costs of Austrian railways, Munduch et al. (2002) used a similar methodological approach. They found that the estimated marginal costs cover between $20 \%$ and $30 \%$ of average infrastructure maintenance costs. They further found that the length of the section and transported gross tonnes are the largest cost producers. At the same time, it is important to note that marginal costs are higher at secondary or local railway lines. When evaluating the marginal cost of rail infrastructure, Tervonen and Pekkarinen (2007) took into account the short-term variable costs. Traffic management costs and operating infrastructure costs are fixed in the short term. Tervonen and Pekkarinen also considered the total gross tonnes transported for both passenger and freight transport. When estimating marginal costs in a dynamic context, Andersson (2008) adopted a similar approach and noted that the ratio between marginal and average costs is very low, resulting in higher rail infrastructure co-financing by the state.

The research presented here focused on finding a charging model for the use of regional railway lines, which - due to geographical and technological characteristics - are neglected and unused yet have great potential, particularly for freight transport. Due to the low freight potential on certain regional routes, the offer of rail freight services is quite poor. At the same time, the quality of regional railway lines and low demand for rail services do not attract rail carriers to offer their services on these routes. For these reasons, companies decide to use road transport, which is more flexible.

Based on preliminary findings mainly focused on the entire rail network, the aim of the present research was to estimate marginal costs of infrastructure maintenance for Slovenian regional railway lines. With this in mind, an econometric cost function model was developed that also includes the most important explanatory variables selected on the basis of previous research and expert judgement. The estimated marginal costs form the basis of calculating charges, which are currently based on train-km. However, calculation on the basis of full costs and train- $\mathrm{km}$ is not focused on the efficient use of infrastructure, because the share of empty wagons on regional routes is between 40 and $50 \%$ (SR, 2014). However, in the current model, this has no effect on determining the charge. The economic effects on railway transport service providers were estimated based on the calculated charges. The findings offer a choice of the most suitable charging model and facilitate infrastructure managers to increase efficiency in terms of the use of regional railway lines, which is currently $40-60 \%$ of line capacity, whereby more than $80 \%$ is represented by passenger traffic (SR, 2014). The latter, however, is exempt from charges in that it is a public service (GRS, 2012).

\section{Methodology}

Relevant data obtained from the company Slovenian Railways were first defined. This was followed by a definition of the cost function econometric model and calculation of the marginal costs and charges, which represent the cost for the rail carrier. Slovenia adopted full-cost pricing based on train-km. However, this has proven to be ineffective in improving regional rail freight transport. Therefore, the research hypothesis is: marginal cost pricing based on gross tonne kilometres (grt.km) is economically efficient.

\subsection{Description of data}

The analysis focuses on the regional railway lines in Slovenia, which are divided into 28 segments (SR, 2014). Due to indirect connections on the Slovenian railway network (Figure 1) and lack of data, one section of regional railway lines was excluded, which represents $1 \%$ of the total regional railway lines. Given this small percentage, this was not considered significant. Thus, in the model, 27 regional line sections in 2012 were analysed, meaning a total of 27 observations.

The research included only variable costs of short-term infrastructure maintenance (Link and Maibach, 1999). The explanatory variables of the cost function model were defined on the basis of Slovenian legislation in the field of rail transport (RoS, 2011) and relevant research conducted in other countries (Johansson and Nilsson, 2004; Munduch et al., 2002). For each section of regional railway studied, information on the technical characteristics of the infrastructure and the statistics 


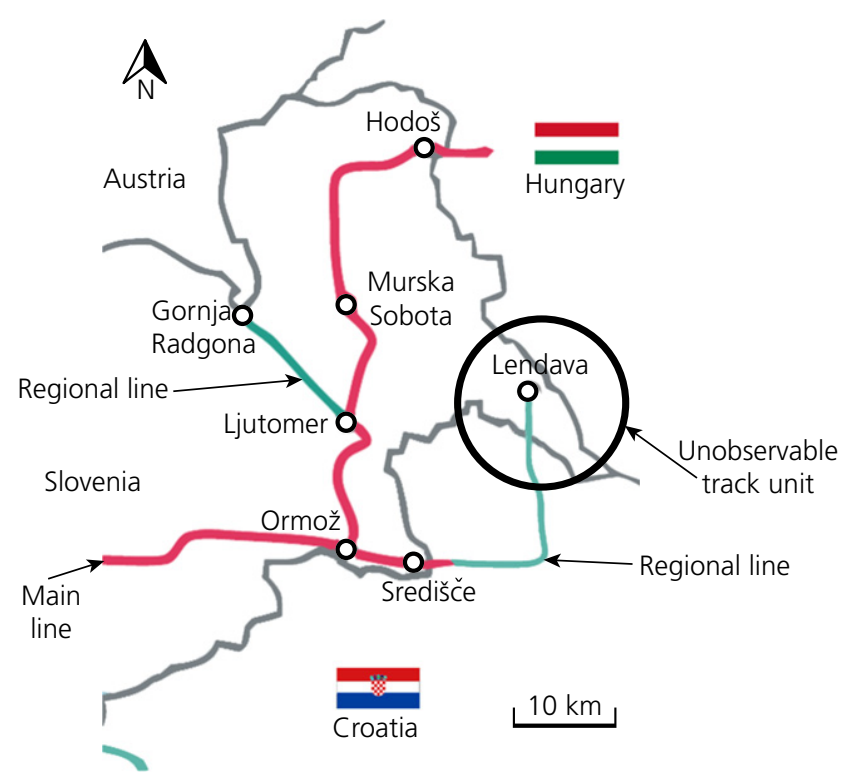

Figure 1. Excluded section of regional rail lines

of Slovenian Railways were obtained. The dependent and explanatory variables are shown in Table 1 . Variable maintenance costs include the costs of ordinary and major maintenance on railway infrastructure. To structure the cost function, variables such as the length of each section, the number of signals, the number of switches and the number of level crossings were taken into account. The quality of the track was determined on the basis of measurements of track geometry parameters taken at least once per year. Track geometric quality is based on track maintenance criteria of vertical alignment, lateral alignment, gauge and twist (UIC, 2005). Lower track geometry parameters mean a higher quality railway line, resulting in no need for additional maintenance that clearly would affect cost increases.

\subsection{Cost function model}

Maintenance costs are influenced by many different factors. Hence, when evaluating the cost function, multiple regression analysis in the form of a double logarithmic model was used. The model is based on neoclassical economic theory of the Cobb-Douglas production function, on the basis of which
Keeler (1974) formulated a cost function in the short term. A similar methodology was used in relevant studies on other countries (Johansson and Nilsson, 2004; Munduch et al., 2002; Tervonen and Pekkarinen, 2007). The applied cost function has the form

$$
\begin{aligned}
\log C_{i}= & a_{0}+a_{1} \log \left(\mathrm{km}_{i}\right)+a_{2} \log \left(\mathrm{grt}_{i}\right) \\
& +a_{3} \operatorname{sig}_{i}+a_{4} \mathrm{Swt}_{i}+a_{5} \mathrm{cross}_{i}+a_{6} \operatorname{tg}_{i} \\
& +a_{7} \log \left(\mathrm{grt}_{i}\right) \times \operatorname{sig}_{i}+a_{8} \log \left(\mathrm{grt}_{i}\right) \times \mathrm{swt}_{i} \\
& +a_{9} \log \left(\mathrm{grt}_{i}\right) \times \operatorname{cross}_{i}+a_{10} \log \left(\mathrm{grt}_{i}\right) \times \operatorname{tg}_{i}+\varepsilon_{i}
\end{aligned}
$$

in which $\mathrm{km}$ represents the track length, grt represents gross tonnes, sig is the number of signals, swt is the number of switches, cross is the number of level crossings and tg represents track geometric quality, which is based upon track maintenance criteria as mentioned earlier. The model was estimated using the least-squares method in the programme EViews 8.0.

The Ramsey reset test was performed to test the functional forms of the regression model. To confirm the assumptions of multiple regression (Greene, 2002; Gujarati and Porter, 2009), the premise for the analysis of multi-colinearity was assessed using the variance inflation factor, whereas for the homoscedastics the White test was performed. The presence of autocorrelation was checked using the Durbin-Watson test and the test of normality of errors was checked using histogram errors and the Jarque-Bera test.

\subsection{Estimation of charges based on marginal cost}

Using the existing model (SR, 2014), the usage charge was calculated using

2. $U=\left(\sum_{i=1}^{I} \sum_{\mathrm{vv}=1}^{\mathrm{vv}} Q_{\mathrm{vl} . \mathrm{km}(\mathrm{vv}, i)} \times F_{\mathrm{vv}} \times P_{i} \times C_{\mathrm{vl} . \mathrm{km}} \times C_{\mathrm{vp}}\right)$

Using the model based on marginal costs, the charge was calculated using the equation

3. $U=Q_{\text {grt.km }} \times \mathrm{MC}_{\text {grt.km, } i} \times P_{i}$

Table 1. Section data

\begin{tabular}{llrrrrrr} 
Variable & Description & Mean & Median & Maximum & Minimum & Standard deviation \\
\hline C & Variable maintenance costs & $92469 \cdot 38$ & $52291 \cdot 36$ & $44198 \cdot 60$ & $3345 \cdot 34$ & $91444 \cdot 14$ \\
km & Track length & $21 \cdot 52$ & 16.00 & $73 \cdot 00$ & $2 \cdot 00$ & $17 \cdot 34$ \\
grt & Gross tonnes & $822535 \cdot 30$ & $682533 \cdot 00$ & $3016851 \cdot 00$ & $29736 \cdot 00$ & $698922 \cdot 30$ \\
sig & Number of signals & $16 \cdot 33$ & $14 \cdot 00$ & $47 \cdot 00$ & 0 & 12 \\
swt & Number of switches & $23 \cdot 18$ & $21 \cdot 00$ & $59 \cdot 00$ & 0 & $17 \cdot 27$ \\
cross & Number of level crossings & $24 \cdot 15$ & $14 \cdot 00$ & $77 \cdot 00$ & 0 & $22 \cdot 84$ \\
tg & Track geometry & $193 \cdot 37$ & $190 \cdot 00$ & $255 \cdot 00$ & $133 \cdot 00$ & $30 \cdot 48$
\end{tabular}


The marginal cost (MC) was calculated from the cost function using Equations 4-6, based on a similar methodology in reference studies (Johansson and Nilsson, 2004; Munduch et al., 2002; Tervonen and Pekkarinen, 2007) where the most suitable unit of marginal costs was found to be grt.km.

4.

$$
\begin{aligned}
\mathrm{MC}_{i} & =\frac{\partial \hat{C}_{i}}{\partial \operatorname{grt}_{\mathrm{km}}}=\frac{\partial \hat{C}_{i}}{\partial \operatorname{grt}_{i}} \times \frac{1}{\mathrm{~km}_{i}} \\
& =\left(\frac{\partial \hat{C}_{i}}{\partial \operatorname{grt}_{i}} \times \frac{\mathrm{grt}_{i}}{\hat{C}_{i}}\right) \times \frac{\hat{C}_{i}}{{\mathrm{grt} . \mathrm{km}_{i}}}
\end{aligned}
$$

whereby

5. $\left(\frac{\partial \hat{C}_{i}}{\partial \operatorname{grt}_{i}} \times \frac{\operatorname{grt}_{i}}{\hat{C}_{i}}\right)=a_{2}+a_{7} \operatorname{sig}_{i}+a_{8} \mathrm{swt}_{i}$

$$
+a_{9} \operatorname{cross}_{i}+a_{10} \operatorname{tg}_{i}
$$

and

6. $\hat{C}_{i}=\exp \left[\log \left(C_{i}\right)+0 \cdot 5(\text { standard error })^{2}\right]$

$\left[\left(\partial \hat{C}_{i} / \partial \operatorname{grt}_{i}\right) \times\left(\operatorname{grt}_{i} / \hat{C}_{i}\right)\right]$ represents the elasticity depending on gross tonnes.

In rail freight transport, it is important to know the influence of the explanatory variables on the cost of infrastructure maintenance; such knowledge can also improve the efficiency of the railway infrastructure capacity use. From an infrastructure manager's viewpoint, elasticity is important in relation to the length of the rail line segment and the transported volume of goods. The length of the rail line segment affects decisions on expansion of the railway network and capacity increases, while the volume transported affects better utilisation of trainsets and increases the volume of freight.

For the observed sections, the weighted marginal costs based on grt.km (Equation 7) were calculated using comparisons with research carried out in other countries.

7. $\overline{\mathrm{MC}}=\sum\left(\mathrm{MC}_{i} \times \frac{\text { grt. } \mathrm{km}_{i}}{\sum \text { grt.km }}\right)$

\section{Results}

\subsection{Numerical results}

The choice of the most appropriate model for estimating maintenance costs of the railway infrastructure was carried out on the basis of expert recommendations (Greene, 2002; Gujarati and Porter, 2009). The exclusion of individual explanatory variables was based on the value of the determination coefficient, $F$-statistics, $t$-statistics of individual variables and Schwarz and Akaike criteria. For comparisons among models, an adjusted $R^{2}$ for degrees of freedom according to the sample size and number of explanatory variables was used. Despite the small sample and the small number of explanatory variables, the adjusted determination coefficient was high, which indicates the suitability of the selected model. The final design of the cost function was

$$
\text { 8. } \begin{aligned}
\log C_{i}= & a_{0}+a_{1} \log \left(\mathrm{km}_{i}\right)+a_{2} \log \left(\mathrm{grt}_{i}\right) \\
& +a_{3} \log \left(\mathrm{grt}_{i}\right) \times \operatorname{sig}_{i}+a_{4} \log \left(\mathrm{grt}_{i}\right) \times \mathrm{swt}_{i} \\
& +a_{5} \log \left(\mathrm{grt}_{i}\right) \times \operatorname{cross}_{i}+a_{6} \log \left(\mathrm{grt}_{i}\right) \times \operatorname{tg}_{i}+\varepsilon_{i}
\end{aligned}
$$

\begin{tabular}{|c|c|c|c|c|}
\hline Coefficient & & Standard error & t-statistic & Probability \\
\hline$a_{0}$ & 4.656919 & $1 \cdot 549681$ & 3.005083 & $0.0070^{\mathrm{a}}$ \\
\hline $\log \left(k m_{i}\right)$ & 0.939195 & 0.166929 & 5.626305 & $0.0000^{a}$ \\
\hline $\log \left(\mathrm{grt}_{i}\right)$ & 0.238966 & $0 \cdot 109124$ & $2 \cdot 189862$ & $0.0406^{a}$ \\
\hline $\log \left(\operatorname{grt}_{i}\right) \times \operatorname{sig}_{i}$ & 0.001761 & 0.000905 & 1.945803 & $0.0659^{b}$ \\
\hline $\log \left(g r t_{i}\right) \times s w t_{i}$ & -0.000922 & 0.000491 & $-1 \cdot 876512$ & $0.0753^{b}$ \\
\hline $\log \left(\operatorname{grt}_{i}\right) \times$ cross $_{i}$ & -0.000774 & 0.000434 & -1.783029 & $0.0898^{b}$ \\
\hline $\log \left(g_{r t}\right) \times \operatorname{tg}_{i}$ & 0.000321 & 0.000263 & $1 \cdot 218787$ & 0.2371 \\
\hline$R^{2}$ & 0.831081 & & Mean dependent variable & 11.014530 \\
\hline Adjusted $R^{2}$ & 0.780405 & & Standard deviation dependent variable & 1.012351 \\
\hline Standard error of regression & 0.474397 & & Akaike criterion & $1 \cdot 564870$ \\
\hline Sum squared residuals & $4 \cdot 501054$ & & Schwarz criterion & 1.900828 \\
\hline Log likelihood & $-1 \cdot 412575$ & & Hannan-Quinn criterion & 1.664768 \\
\hline F-statistic & $16 \cdot 399990$ & & Durbin-Watson statistic & 1.889569 \\
\hline Probability (F-statistic) & 0.000001 & & & \\
\hline
\end{tabular}

The estimated model parameters of the cost function and the test statistics are shown in Table 2.

Table 2. Estimated parameters 


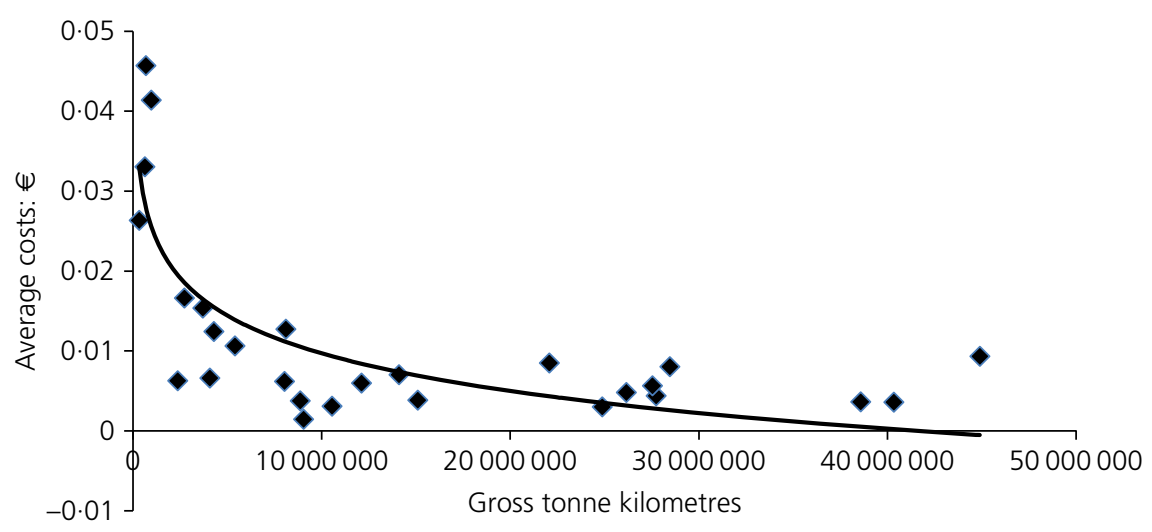

Figure 2. Average costs

All estimated parameters except the parameter $\log \left(\mathrm{grt}_{i}\right) \times \operatorname{tg}_{i}$ were statistically significant at the $5 \%$ or $10 \%$ characterising level. The adjusted determination coefficient was $0 \cdot 78$, which indicates the high power of the variable cost model. The regression function of estimating costs was specified correctly, given that the Ramsey reset test showed an $F$-statistic of 0.66 (probability 0.4239 ). The problem of multi-colinearity between regressions was not detected because the values of the variance inflation factor were considerably lower than 10. The White test showed that heteroscedasticity between variances of conditional distributions was not present. The Durbin-Watson test indicated no positive or negative autocorrelation, as the value of the coefficient (1.8896) was in the range $1 \cdot 743-2 \cdot 257$ at $1 \%$ statistical significance.

A histogram of the residuals showed a normal distribution. The Jarque-Bera test indicated a JB-statistic of 0.2362 and a probability of $88 \%$. Moreover, the skewness and kurtosis coefficients were $0 \cdot 13$ and $3 \cdot 37$, respectively. The calculated coefficients indicate that the hypothesis should not be rejected and that the residuals were normally distributed.

Given the length of the segment, the cost elasticity was determined to be 0.94 whereas, in terms of gross tonnes, it was only $0 \cdot 24$. The findings show that by increasing transported gross weight by $1 \%$, the variable costs of infrastructure maintenance increase by $0 \cdot 24 \%$. Similar results were found in relevant research in other countries (Johansson and Nilsson, 2004; Munduch et al., 2002; Tervonen and Pekkarinen, 2007). Due to cost inelasticity, the average costs of railway infrastructure maintenance decrease (Figure 2) with each transported cargo. Lower than average marginal costs contribute to the economies of scale.

Railway infrastructure is a natural monopoly and as such is often ineffective, which is why subsidies are required. Theoretically, the best approach for charging fees is one that is based on marginal social costs (Nilsson, 1992) but, because
Table 3. Estimated marginal costs

\begin{tabular}{|c|c|c|c|}
\hline \multicolumn{4}{|c|}{ Marginal costs: $€$} \\
\hline Slovenia & $\begin{array}{c}\text { Finland } \\
\text { (Tervonen and } \\
\text { Pekkarinen, 2007) }\end{array}$ & $\begin{array}{l}\text { Austria } \\
\text { (Munduch } \\
\text { et al., 2002) }\end{array}$ & $\begin{array}{l}\text { Sweden } \\
\text { (Johansson and } \\
\text { Nilsson, 2004) }\end{array}$ \\
\hline $0.00188^{a}$ & $0.0018^{b}$ & $0.00309^{e}$ & $0.001023^{f}$ \\
\hline $0.00115^{c}$ & $0.0019^{d}$ & & \\
\hline
\end{tabular}

aWeighted marginal cost for 2012

bWeighted marginal cost from cross-section data for 1997

Weighted marginal cost (in prices of 2000)

'Weighted marginal cost from cross-section data (in prices of 2000)

eWeighted marginal cost from panel data in constant prices with respect to the base year 2000

${ }^{f}$ Weighted marginal cost from cross-section data in Sweden (base year 2000)

of the deficit caused by railway infrastructure, various additional fees are used. Increased utilisation of the railway infrastructure would bring about greater efficiency, which is also the aim of development of the rail market.

From a scientific viewpoint, the results of the econometric analysis of maintenance costs are comparable with those in other reference studies. In line with the literature, the estimated variables were statistically significant. Deviations between the calculated marginal costs result from differences in labour costs between countries in 2012 (Eurostat, 2014), given that labour costs account for more than $60 \%$ of maintenance costs (SR, 2014). The biggest difference between the calculated marginal costs (Table 3) is between Slovenia and Austria, which are also most comparable in terms of the railway system. According to Eurostat, labour costs per hour are almost three times higher in Austria than in Slovenia.

Based on the estimated cost function, the marginal costs were calculated with the basis of calculating charges based on grt.km. The charge based on marginal costs is favourable for 


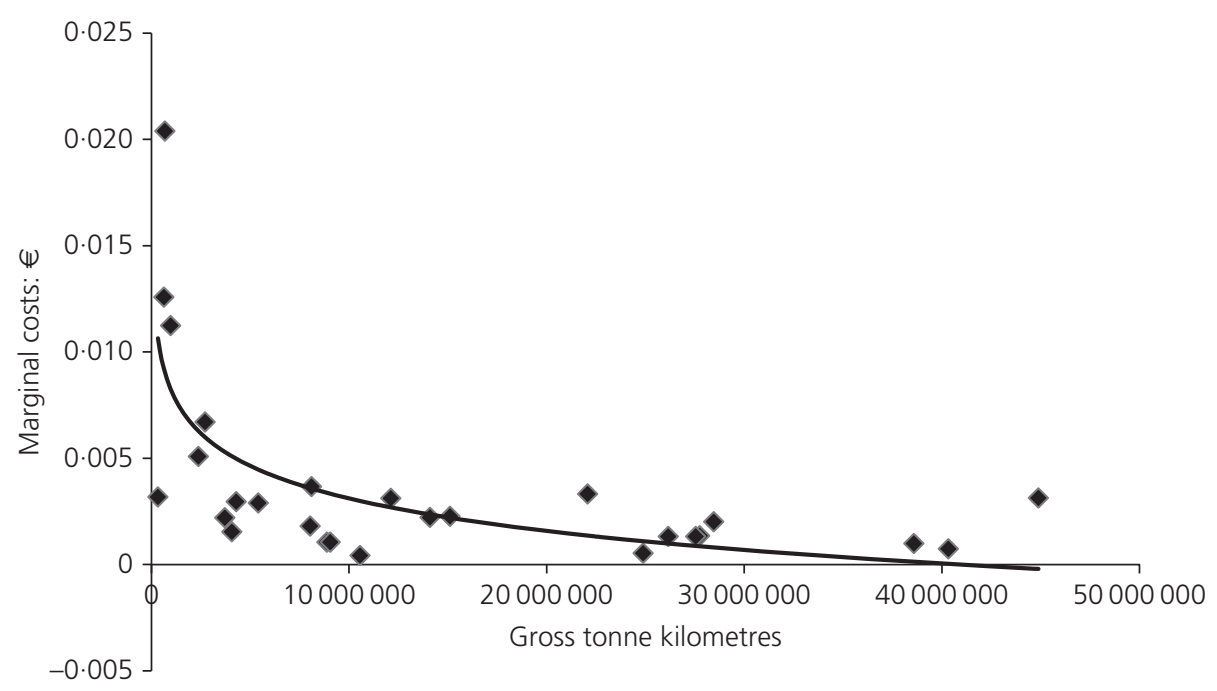

Figure 3. Marginal costs

railway carriers and has a positive impact on their business. It also offers the possibility of increasing the supply of rail freight transport services.

\subsection{Effects on existing model}

Marginal infrastructure maintenance costs were calculated on the basis of Equations 4, 5 and 7. The marginal costs per segment were calculated to range between $€ 0.0004$ and $€ 0.0204$ per grt.km per year and the weighted marginal costs for all sections of regional lines to $€ 0.001888$ per grt.km per year. As shown in Figure 3, the marginal costs decrease with grt.km, indicating that increasing the volume of cargo carried by rail would seem reasonable.

The current model is based on total maintenance and traffic management costs and is calculated on the basis of train $-\mathrm{km}$. In 2012, the charge was €161 310 excluding VAT, taking into account that the coefficient category of towing vehicles was 1 and the rate of deduction was $0 \cdot 72$, given that, on average, trains weigh less than $1000 \mathrm{t}$. The power cars are divided into three categories (A, B and C) with appurtenant coefficients and the weight of the power cars is taken into account when calculating the usage charge. Since power cars in categories $\mathrm{B}$ and $\mathrm{C}$ are mostly used on regional tracks, the relevant coefficient was here taken to be 1 . The price per train-km is $€ 1.133$ excluding VAT, with weighting categories for tracks summarised using the Network programme (SR, 2014).

When using the grt.km calculation and different prices for the sections, the charge was $9 \cdot 79 \%$ lower than that calculated with the existing model. Positive economic effects from the proposed model are on the carrier's side, particularly in the sections where the most grt.km are moved. The function of marginal cost is decreasing, which means that increasing grt.km results in increased positive economic impact on carriers. Increasing transported gross tonnes will not result in higher variable costs of maintaining infrastructure, as variable costs are inelastic with respect to transported gross tonnes.

Using the model based on grt.km also has a positive influence on empty wagons. The latter did not have a cost impact in the existing model since most freight trains on regional rail lines do not exceed $1000 \mathrm{t}$, which means a price deduction of $0 \cdot 72$. In the proposed model, however, empty wagons contribute to a greater gross tonne weight.

A change in the calculation model brings about positive direct and indirect effects. The hypothesis set in Section 2 can thus be confirmed. Based on calculations of the maximum economic benefit, the most appropriate model is the one based on grt.km. In the short term, revenues for infrastructure managers will be reduced. However, by increasing the gross tonnage of transported goods, operator revenues will increase. Due to inelasticity, the variable costs of maintaining infrastructure will not increase.

\section{Conclusions}

This research has shown that changing the current model for calculating usage charge would bring economic effects for both infrastructure managers and carriers. It should be noted that calculating the usage charge by the proposed method maximises economic benefits and reduces costs for the carriers.

The effects would be negative for infrastructure managers in the short run, since direct revenues from usage charges will be 
reduced. By increasing transported gross tonnes of goods, revenues for operators will increase but, due to their inelasticity, the variable costs of infrastructure maintenance will not. With an increase in goods transported by rail there will also be wider positive economic effects due to reduced external costs in comparison with road transport.

The results of the proposed model are also in line with the objectives of European transport policies that strive to increase rail freight transport and redirect the flow of goods from road to rail, which results in significantly lower external costs. The objectives of European transport policies in the field of rail transport also include development of the internal rail market in Europe, where it is necessary to ensure a holistic approach to freight corridor management. Efficiency in the corridors, however, cannot be improved without effective links to the regional areas that, in terms of global integration, are neglected. Regional railway lines, nevertheless, represent a potential that remains untapped. In addition, regional areas in the field of railway transport and charging are poorly explored, with most studies focusing on the main railway lines. By establishing a system that will facilitate railway transport as part of the state, regional routes could be utilised more efficiently. To this end, in addition to economic criteria, organisational criteria also need to be taken into account because existing organisations are failing to support the satisfactory development of regional infrastructure.

Use of the proposed model can contribute to the sustainable development of transport systems, given that ongoing globalisation is increasing the flow of goods, with consequent negative impacts on the environment due to greater use of road transport. Furthermore, increased road transport has a negative impact on road infrastructure, with more than $50 \%$ of national roads in Slovenia already in very poor condition (SIA, 2015). Comprehensive solutions for regional rail transport are thus required.

Development of the rail market will require major changes that contribute to increasing rail's market share. Solving problems unilaterally is often not sufficient comprehensive solutions are needed as systems are interdependent and cannot operate as effectively in isolation. Competitive railway systems and sustainable transport development can be achieved by including regional railway lines.

\section{REFERENCES}

Andersson M (2008) Marginal railway infrastructure costs in a dynamic context. European Journal of Transport and Infrastructure Research 8(4): 268-286.

Brown R, Caves D and Christensen L (1979) Modelling the structure of costs and production for multiproduct firms. Southern Economic Journal 46(1): 256-273.
Christensen L, Jorgenson D and Lau L (1973) Transcendental logarithmic production frontiers. Review of Economics and Statistics 55(1): 28-45.

EC (European Community) (1991) Council Directive 91/440/EEC of 29 July 1991 on the development of the Community's railways. Official Journal L237.

EC (2012) Directive 2012/34/EU of the European Parliament and of the Council of 21 November 2012 establishing a single European railway area. Official Journal of the European Union L343/32.

ECMT (European Conference of Ministers of Transport) (1998) User Charges for Railway Infrastructure. OECD Publishing, Paris, France, round table no. 107.

ECMT (2005) Railway Reform \& Charges for the Use of Infrastructure. ECMT, Paris, France.

European Commission (2001) White Paper. European Transport Policy for 2010: Time to Decide. European Commission, Brussels, Belgium. See http://ec.europa.eu/transport/themes/strategies/2001_ white_paper_en.htm (accessed 05/05/2015).

European Commission (2011) White Paper. Roadmap to a Single European Transport Area - Towards a Competitive and Resource Efficient Transport System. European Commission, Brussels, Belgium. See http://ec.europa.eu/transport/themes/strategies/2011_ white_paper_en.htm (accessed 25/05/2015).

Eurostat (2014) Hourly Labour Costs Ranged from 3.7 to 40.1 EUR Across the EU28 Member States in 2013. Eurostat, Luxembourg.

Greene WH (2002) Econometric Analysis. Prentice Hall, Upper Saddle River, NJ, USA.

GRS (Government of the Republic of Slovenia) (2012) Decision of the Government of the Republic of Slovenia Number 375-24/2011/49-0064533. GRS, Ljubljana, Slovenia.

Gujarati DN and Porter DC (2009) Basic Econometrics, 5th edn. McGraw-Hill, New York, NY, USA.

Johansson P and Nilsson JE (2004) An economic analysis of track maintenance costs. Transport Policy 11(3): 277-286.

Johnson D and Nash C (2008) Charging for scarce rail capacity in Britain: a case study. Review of Network Economics 7(1): 53-76.

Keeler TE (1974) Railroad costs, returns to scale and excess capacity. The Review of Economics and Statistics 56(3): 201-208.

Li X and Preston J (2015) Reassessing the financial and social costs of public transport. Proceedings of the Institution of Civil Engineers - Transport 168(4): 356-369, http://dx.doi.org/10.1680/ tran.12.00096.

Link H and Maibach M (1999) Calculating Transport Infrastructure Costs. DIW/INFRAS Consulting, Berlin, Germany.

Munduch G, Pfister A, Sögner L and Stiassny A (2002) Estimating Marginal Costs for the Austrian Railway System. Department of Economics, Vienna University of Economics \& BA, Vienna, Austria, Working Paper 78.

Nash C (2005) Infrastructure charges in Europe. Journal of Transport Economics and Policy 39(3): 259-278.

Nash C and Matthews B (2003) Rail Infrastructure Charges - The Issue of Scarcity. Association for European Transport, Henley-in-Arden, UK.

Nilsson JE (1992) Second-best problems in railway infrastructure pricing and investment. Journal of Transport Economics and Policy 26(3): 245-259.

Quinet E (2001) European pricing doctrines and the EU reform. Proceedings of the First IMPRINT Seminar, Brussels, Belgium.

RoS (Republic of Slovenia) (2011) Railway Transport Act. Official Gazette of the Republic of Slovenia 11/2011. 
SIA (Slovenian Infrastructure Agency) (2015) Action Plan Reconstruction of Main and Regional Roads. SIA, Ljubljana, Slovenia.

SR (Slovenian Railways) (2014) Network Statement of the Republic of Slovenia 2014. Slovenian Railways, Ljubljana, Slovenia.

Tervonen J and Pekkarinen S (2007) Marginal Rail Infrastructure Costs in Finland 1997-2005. Finnish Rail Administration, Helsinki, Finland.
UIC (International Union of Railways) (2005) UIC Code 518:

Testing and approval of railway vehicles from the point of view of their dynamic behaviour. UIC, Paris, France.

Van de Velde D, Nash C, Smith A et al. (2012) EVES-Rail-Economic Effects of Vertical Separation in the Railway Sector. Community of European Railways and Infrastructure Companies, Brussels, Belgium, Summary Report.

\section{How can you contribute?}

To discuss this paper, please email up to 500 words to the editor at journals@ice.org.uk. Your contribution will be forwarded to the author(s) for a reply and, if considered appropriate by the editorial board, it will be published as discussion in a future issue of the journal.

Proceedings journals rely entirely on contributions from the civil engineering profession (and allied disciplines). Information about how to submit your paper online is available at www.icevirtuallibrary.com/page/authors, where you will also find detailed author guidelines. 